\title{
Precisamos de uma arquitetura política para resistir a uma arquitetura civilizatória
}

We need a political architecture to resist a civilizing architecture

Fernando Luiz Lara*

*Fernando Luiz Lara works on theorizing spaces of the Americas with emphasis on the dissemination of architecture and planning ideas beyond the traditional disciplinary boundaries. In his several articles Prof. Lara has discussed the modern and the contemporary architecture of our continent, its meaning, context and social-economic insertion. His latest publications include Excepcionalidad del Modernismo Brasileño; Modern Architecture in Latin America (Hamilton Award runner up 2015) and Quid Novi (Anparq best book award 2016). Prof. Lara holds the Potter Rose Professorship in Urban Planning at the University of Texas at Austin where he currently serves as Director of the PhD Program in Architecture. fernandoluizlara@gmail.com.

\section{Palavras-chave:}

Arquitetura,

Descolonização,

Resistência Política.

\section{Keywords:}

Architecture,

Decolonization,

Political Resistance.

\section{Resumo}

A Arquitetura sempre foi um mecanismo de controle territorial. A missão

civilizadora embutida em nossa profissão vem com uma camada de colonialidade da qual precisamos primeiro estar conscientes e depois subverter. Arturo Escobar em sua discussão explica a colonização co-
mo algo inerente à modernização, sendo nossa civilização e nossos mo algo inerente a modernização, sendo nossa civilização e nossos que nos cercam hoje. A questão resultante diz respeito ao papel da arquitetura como ferramenta e resultado de tal modernização/colonização e os possíveis antídotos que eu acredito se encontrarem na esfera política.

\section{Abstract}

Architecture has always been a tool for spatial control. The civilizing mission imbedded in our profession comes with a layer of coloniality that we need to first be aware of and then subvert. Arturo Escobar's discussion of colonization as something inherent to modernization explains that our civilization and our civilizing processes are directly responsible for the social evils that circle us today. The question that comes regards the role of architecture as both a tool and a result of such modernization/colonization and the possible antidotes that I believe lies in the political realm.

\section{usjt}

arq.urb

número 29 | set - dez de 2020

Recebido: 06/02/2020

Aceito: $21 / 05 / 2020$. 
Precisamos de uma arquitetura política para resistir a uma arquitetura civilizatória.

Mesmo antes da pandemia do Covid-19, que nos colocou em quarentena, as feias facetas de nossa civilização ocidental já eram visíveis: desigualdades insuportáveis, utilização insustentável de recursos, sexismo profundamente enraizado, racismo e xenofobia. Proponho que pensemos em todos os males que acabamos de mencionar e em tantos outros como sendo componentes inerentes aos nossos processos civilizatórios, e que pensemos nos processos políticos como a única solução possível para os desafios hercúleos de superá-los.

Sei que parece contra intuitivo, pois, de acordo com o senso comum predominante, a civilização é algo que todos devem aspirar e a política; bem, a política é o trabalho sujo de forçar e restringir o caminho inevitável de nossa civilização ocidental.

Discordo das normas estabelecidas aqui, pois vejo a colonização em todo ato de modernização que está no cerne da hegemonia ocidental. O trabalhos de Walter Mignolo e Arturo Escobar já são conhecidos o suficiente para que eu não precise explicar quem eles são e a razão pela qual o que eles escreveram é importante. No entanto, suspeito que poucos colegas arquitetos e até mesmo os teóricos da arquitetura ainda não compreenderam completamente as consequências da dupla modernidade/colonialidade (como são conhecidos) na desconstrução de muitos princípios de nossa disciplina.

Nesse sentido, peço desculpas por qualquer redundância, mas começarei lembrando a todos que a civilização está enraizada no termo latino Civitas, que significa o corpo social dos cidadãos unidos pela lei. Na linguagem contemporânea, civitas nos deu cidade, civilização, cidadania. Polis é uma palavra grega que também significa um grupo de cidadãos que concordou com certas regras e costumes. Usado como sinônimo de cidade, o termo polis nos deu política, mas também política, polidez, polícia. Mas suas semelhanças terminam aqui. A ideia grega de polis implica grupos menores de pessoas decidindo suas regras e costumes, enquanto a ideia romana de civitas implica a imposição da lei sobre a população em geral. Polis é popular, civitas é de cima para baixo.

Voltando à análise paradigmática da colonialidade de Arturo Escobar, como algo inerente à modernização, não é difícil entender que nossa civilização e nossos processos civilizatórios são diretamente responsáveis pelos males sociais que nos cercam hoje.

A raiz de nossa civitas/modernidade está na separação de Rene Descartes entre res cogitans (mente) e res extensa (tudo mais), a mente dos homens europeus agora era 'mestra' de tudo o que não é apenas terra e recursos, mas também todas as mulheres e todos os homens não- europeus. Para Descartes, não há alma ou mente na natureza, apenas nos homens, anjos e Deus.

Essa síntese fez com que Descartes perdesse apenas para Platão na tradição ocidental. Em um artigo recente publicado no The Plan Journal. Eu me debrucei na história de como a ocupação das Américas desencadeou transformações na área de arquitetura que não tínhamos examinado antes. Na palavra do estudioso argentino Roberto Fernandez, "nenhum território esteve mais próximo de uma pura modernidade, das utopias renascentistas à aplicação enérgica das ideias de contrarreforma (1600), iluministas (1700) e positivistas (1800)."

Não me interpretem mal, eu comemoro muitas das conquistas de nossa modernização cartesiana, como água potável, saneamento, vacinas, enciclopédias de bolso e viagens aéreas (ou qualquer novo formato de visita a diferentes pessoas e lugares que teremos após a pandemia do Covid-19). Mas não posso fechar os olhos ao fato de que essa modernização/civilização foi construída para beneficiar o homem branco, às custas de todos que não são brancos e não são homens.

A questão que se coloca é sobre o papel da arquitetura nesse processo. Desde os tratados militares do século XVI, que usavam a geometria (desenvolvida no norte e no sul do Mediterrâneo) para otimizar a ocupação europeia das Américas, até as redes que transformaram as terras ameríndias em mercadorias a serem compradas e vendidas junto com milhões de corpos africanos, a nas igrejas e capelas que deram um raciocínio divino a essas tragédias, a história da arquitetura se sobrepõe à modernização / civilização hegemônica que nos trouxe aqui agora.

É claro que é fácil apontar para séculos atrás e ver a colonialidade nas ações de reis, cardeais, conquistadores e coronéis. Mais difícil é ver a colonialidade ou 0 lado sombrio de nossa civilização em belos edifícios que não apenas admiramos, como também celebramos diariamente em nossos seminários, palestras e escritos.

Começando em ordem cronológica, raramente discutimos o fato de que a Unité 
d'Habitacion de Corbusier foi construída para "civilizar" os norte-africanos que estavam emigrando para a França continental e tinham Marselha como seu principal porto. A história do povo Pieds-Noirs (pés escuros) não pode ser separada da decisão do governo francês de construir a primeira Unité em Marselha para Corbusier, sempre tentando ver sua arquitetura como uma ferramenta civilizatória. Quando usamos a abordagem teórica da colonialidade /modernidade para examinar a arquitetura moderna, percebemos que ela funcionou como um instrumento de expulsão e controle em todos os lugares.

Fabiola Lopez-Duran encontrou em Eugenics in the Garden várias referências às ideias da eugenia da supremacia branca nos cadernos de Le Corbusier. Os mesmos cadernos que dezenas de estudiosos haviam estudado antes e optaram por não ver as referências eugênicas. Apesar de a terem inventado e beneficiado, os europeus não têm o monopólio da colonialidade. O campus da UNAM desalojou um Ejido - terra comum - na periferia no sul de Cidade do México, o icônico Crown Hall de Mies desalojou um prédio de apartamentos (coincidentemente chamado Meca) que abrigava uma próspera comunidade afro-americana.

Muitos de nossos famosos edifícios modernistas no Rio de Janeiro foram construídos sobre cortiços violentamente removidos, começando com o prefeito Pereira Passos em 1904 e continuando até o prefeito Eduardo Paes um século depois. Como estudante de arquitetura, há 30 anos, fiquei encantado com as formas ondulantes do Centro Ambiental Balbina, projetado por Severiano Porto. Somente 20 anos depois descobri que Balbina é um dos piores desastres construídos pela engenharia brasileira. Seu lago raso destruiu quilômetros e quilômetros de floresta, desalojando milhares de famílias para gerar apenas 30\% da eletricidade esperada. Como resultado, Balbina gera mais gás de efeito estufa do que uma usina de carvão da mesma capacidade devido à enorme quantidade de metano constantemente liberada pelo lago desde que as operações começaram em 1989.

A arquitetura sempre foi uma ferramenta de controle espacial e o Brasil sempre foi uma enorme máquina de apropriação de terras desde 1500. Sabemos muito pouco sobre os motivos do assassinato de Marielle Franco, mas certamente está ligada à invasão de terras (grilhagem) por milicianos no país, região do Rio de Janeiro. Sabemos um pouco mais sobre como essa terra foi administrada antes da chegada dos portugueses em 1500, mas vale lembrar que a primeira atividade econômica europeia no Brasil foi convencer os nativos a cortar o pau-brasil e en- viá-lo para o outro lado do oceano. Nossa terra recebeu o nome de um processo de desmatamento com mão-de-obra barata para exportar commodities com baixo valor agregado. Que destino!

Para superar esse destino trágico, precisamos descolonizar as histórias de nossa arquitetura, o que implica várias ações:

1. Perceber que não há modernização sem colonização. Para cada Esplanada do Castelo ou Pampulha que construímos, centenas de famílias pobres foram expulsas de suas casas, indenizadas ou não, para que o modernismo se instalasse em toda a sua exuberância.

2. Perceber que cada um desses maravilhosos edifícios existia anteriormente em formas de madeira cortadas em alguma área da Mata Atlântica (no caso do eixo Rio-SP, onde são mais numerosas) e logo depois são preenchidas com aço, calcário e argila escavados de algum outro local.

3. Perceber que ombros pobres (principalmente negros e pardos) carregavam cada um desses materiais em troca de um salário que não Ihes permitia desfrutar da cidade moderna, forçando suas famílias a construir suas próprias casas, sem uma escritura, sem eletricidade, água ou esgoto.

4. Perceber que a arquitetura é parte integrante do processo financeiro da economia, drenando recursos anteriormente investidos em produção e gerando emprego e renda, transportados pelo sistema financeiro para processos deslocados do mundo da produção.

5. Perceber que a arquitetura moderna sempre trouxe consigo um componente moral que raramente apresentava um viés progressivo, como o projeto de empoderamento das mulheres do Conjunto Pedregulho e, na maioria dos casos, normalizava a desigualdade expressa nos quartos de empregada e nos elevadores de serviço. Independentemente do viés progressivo ou reacionário, a arquitetura moderna sempre foi um instrumento da colonialidade no sentido de ensinar às massas como elas devem viver suas vidas.

Existe alguma esperança para uma arquitetura progressiva e verdadeiramente empoderadora no futuro? Ouso ser otimista e responder que sim. Além disso, um experimento brasileiro chamado Orçamento Participativo já provou ser um poderoso instrumento de organização e empoderamento da comunidade.

Criado pelos prefeitos do Partido dos Trabalhadores no final dos anos 80, o Orçamento Participativo descortinou partes da sociedade que haviam sido excluídas há 
séculos. Permita-me divergir um pouco para discutir o fato de que a arquitetura sempre foi uma ferramenta de exclusão, embora a vimos como exclusividade. Exclusividade e exclusão são a mesma coisa, uma só existe por causa da outra.

A arquitetura celebra a exclusividade há muito tempo e é hora de entender que a consequência real de um design exclusivo é a exclusão da maioria que não pode estar lá. O que o Orçamento Participativo induziu em Porto Alegre e Belo Horizonte (as duas maiores cidades que mais experimentaram) foi um aumento significativo da participação política e uma popularização dos termos do debate.

Concebido e implementado quando os orçamentos municipais eram apertados, o Orçamento Participativo foi marginalizado quando o crescimento do PIB dos anos Lula trouxe muito dinheiro para as grandes construtoras. Um movimento que surgiu da polis se tornou civitas quando alcançou a complexidade do governo federal. Outros grupos ocuparam o espaço de base, grupos que pregavam religião, violência e ódio.

No lado pessimista, ainda não examinamos completamente o impacto ecológico de todas as linhas que traçamos. Na XII Bienal de Arquitetura de São Paulo, apresentei um estudo da pegada ecológica da Capela da Pampulha (Niemeyer, 1942); da Catedral de Brasília (Niemeyer 1960); do MASP (Bo Bardi 1967) e da FAUUSP (Artigas 1968). Meus alunos no Texas calcularam a degradação mineral desses prédios famosos e o impacto volumétrico que eles deixaram na paisagem. Traçados sobre uma foto aérea do desastre da barragem de Mariana/ Bento Rodrigues de 2016, os quatro edifícios paradigmáticos tinham os buracos que cada um exigia desenhado na escala de Bento Rodrigues coberto de lama tóxica.

Uma arquitetura política no sentido de abrir o processo de tomada de decisão a uma variedade de atores poderia reativar o poder do design como um antídoto para as consequências da colonialidade de nossos esforços de modernização. Arturo Escobar é o precursor com suas publicações sobre o design do pluriverso. Nas suas palavras, deveríamos "perguntar se o design pode realmente contribuir para possibilitar as formas comunitárias de autonomia (...). Mobilizar as comunidades populares da América Latina firmemente no escopo do design, talvez até no centro delas, desejando trabalhar em estreita colaboração com as comunidades em luta". A síntese de Escobar nos ensina que devemos trabalhar "de baixo para a esquerda e com a terra".
A arquitetura contemporânea herdou vários problemas da modernidade, e esses problemas criam muitas camadas de colonialidade. Temos uma indústria que consome uma quantidade insuperável de recursos para criar instrumentos de exclusão, guiados pelo ego de alguns homens brancos "iluminados".

A política de que precisamos agora é exatamente o oposto disso. Os processos participativos / colaborativos "de baixo" são o antídoto para a armadilha de autoria que mantém a arquitetura como refém de alguns egos inflados. A ida para a "esquerda" movimenta a arquitetura para se tornar uma ferramenta de inclusão, abandonando de uma vez por todas a obsessão pela exclusividade que disfarça as forças de exclusão que a sustentam. E "com a Terra" nos lembra que, diferentemente do que Descartes propôs há 400 anos, não estamos separados de todos os outros seres em nosso planeta.

Como estudante de arquitetura, há trinta anos, tive um professor chamado Radamés Teixeira que costumava repetir ad infinitum uma pergunta muito simples para todos nós durante as aulas de design: como o seu projeto torna o mundo um pouco melhor? O professor Radamés agora tem 96 anos. Ele cresceu, estudou e ensinou por quatro décadas, acreditando que a modernização levaria a uma vida melhor, e isso aconteceu em muitos aspectos. Mas ele também entendeu que todas as linhas que traçamos gerarão alguma colonialidade, serão mais ricas que a maioria, abusarão de recursos ecológicos e, muitas vezes, serão o resultado das projeções egoístas do arquiteto. Sua pergunta permanece como um guia para a nossa necessária posição política.

Como o seu projeto torna o mundo um pouco melhor?

\section{Referências}

ESCOBAR, Arturo. Encountering Development, Op.Cit.

FERNANDEZ, Roberto. El Laboratorio Americano, Arquitectura, Geocultura y Regionalismo, Madrid: Biblioteca Nueva, 1997.

LARA, Fernando "American Mirror: the occupation of the "new world" and the rise of architecture as we know it", The Plan Journal, vol 5, n.1, May 2020.

López-Durán, Fabiola. Eugenics in the Garden: Transatlantic Architecture and the Crafting of Modernity. University of Texas Press, 2018. 